\title{
Overexpression of IncRNA AFAP1-AS1 promotes cell proliferation and invasion in gastric cancer
}

\author{
ZHOUXIAO LI ${ }^{1,2^{*}}$, ZHILI DING ${ }^{3 *}$, DAWEI RONG ${ }^{1}$, WEIWEI TANG ${ }^{1}$ and HONGYONG CAO ${ }^{1}$ \\ ${ }^{1}$ Department of General Surgery, Nanjing First Hospital, Nanjing Medical University, Nanjing, Jiangsu 210001, P.R. China; \\ ${ }^{2}$ Department of Plastic and Hand Surgery-Campus Innenstadt, University Hospital Munich, D-80336 Munich, Germany; \\ ${ }^{3}$ Department of Pediatric Intensive Care Unit, Changzhou Children's Hospital, Changzhou, Jiangsu 213018, P.R. China
}

Received February 11, 2018; Accepted June 12, 2019

DOI: $10.3892 / 01.2019 .10640$

\begin{abstract}
Long non-coding RNA (lncRNA) actin filamentassociated protein 1 antisense RNA 1 (AFAP1-AS1) has been revealed to be associated with certain types of cancer. However, whether the IncRNA AFAP1-AS1 is involved in the development and progression of gastric cancer (GC) remains unknown. The present study investigated the clinical significance and biological functions of AFAP1-AS1 in GC. The expression levels of lncRNA AFAP1-AS1 in 52 patients with GC, and in 1 normal gastric mucosal cell line and 3 GC cell lines, were evaluated by reverse transcription quantitative polymerase chain reaction analysis. Small interfering RNAs were used to suppress AFAP1-AS1 expression in GC cell lines. The results indicated that AFAP1-AS1 expression levels were significantly increased in GC tissues and cell lines compared with the corresponding noncancerous tissues and normal gastric cells. In addition, the patients with GC with increased AFAP1-AS1 expression exhibited an advanced clinical stage and an association with the occurrence of lymph node metastasis compared with those with decreased AFAP1-AS1 expression. In vitro assays demonstrated that knockdown of AFAP1-AS1 decreased levels of cell proliferation and migration. In addition, the results of flow cytometry demonstrated that knockdown of AFAP1-AS1 caused cell cycle arrest. In conclusion, AFAP1-AS1 is a novel molecule involved in GC progression, which may be a potential prognostic biomarker and target for therapeutic intervention.
\end{abstract}

Correspondence to: Professor Hongyong Cao or Dr Weiwei Tang, Department of General Surgery, Nanjing First Hospital, Nanjing Medical University, 68 Chang Le Road, Nanjing, Jiangsu 210001, P.R. China

E-mail: caohongy6167@163.com

E-mail: 1243773473twww@sina.com

*Contributed equally

Key words: gastric cancer, tumorigenesis, genes, proliferation, migration invasion

\section{Introduction}

Gastric cancer (GC), a genetic disease involving multiple changes in the genome, remains a primary cause of male mortality in developing countries, with its incidence continuously increasing in recent years $(1,2)$. In spite of the improvements achieved in the techniques employed for diagnosis and treatment, the majority of patients are diagnosed during the advanced stages of disease, and thus suffer a poor prognosis (3-5). Therefore, improving the early diagnosis and treatment of GC is a major strategy for decreasing the rate of mortality.

Over the past few decades, a large number of studies have focused on the aberrant expression of protein-coding RNAs in different types of cancer, which have provided promising approaches for cancer diagnosis and treatment $(6,7)$. However, along with the advances made in high-resolution microarrays and genome-wide sequencing technology, an increasing body of evidence from genomics and transcriptomics studies has suggested that long non-coding RNAs (lncRNAs) may be effective biomarkers for cancer detection and molecular targets for cancer therapy (8-11). The lncRNA actin filament-associated protein 1 antisense RNA 1 (AFAP1-AS1) has been demonstrated to be upregulated in ovarian cancer, gallbladder cancer, esophageal squamous cell carcinoma, pancreatic ductal adenocarcinoma and colorectal cancer (12-16). However, whether lncRNA AFAP1-AS1 is involved in the development and tumorigenesis of GC remains unknown. The aim of the present study was to determine the clinical significance and biological functions of AFAP1-AS1 in GC.

\section{Materials and methods}

Patients and tissue samples. A total of $52 \mathrm{GC}$ samples and the corresponding adjacent tissues were obtained from patients who underwent surgery during October 2013 and August 2015 at Nanjing Hospital Affiliated with Nanjing Medical University (Nanjing, China). The inclusion criteria for patient recruitment were as follows: i) The first diagnosis of the patient is GC (age 20-85 years old); ii) the patients' cardiopulmonary function was confirmed to be normal by pathological examination prior to surgery; 
iii) the patients' blood, liver and kidney function were basically normal; iv) none of the patients received radiotherapy or chemotherapy prior to surgery; and v) all patients were diagnosed with clinical TNM stage (cTNM) I-IV GC (17) and had detailed clinical data and basic personal information available. The exclusion criteria for patient recruitment were: i) Patients who has undergone radiotherapy and chemotherapy prior to surgery; ii) patients who were in poor physical condition and would not be able to tolerate the required examination; iii) patients in which GC was not the primary tumor, but a result of secondary tumor metastasis; and iv) diagnosis of secondary diseases upon admission, in particular other types of cancer besides GC. The tumor tissues and adjacent non-tumor tissue (the distance from tumor surgical margin $\geq 5 \mathrm{~cm}$ ) were collected during surgical resection. All specimens were immediately stored at $-80^{\circ} \mathrm{C}$ in a freezer until subsequent use. The present study was approved by the Ethics Committee of Nanjing First Hospital, Nanjing Medical University (Jiangsu, China). Written informed consent was obtained from all of the patients prior to participation.

$R N A$ isolation, reverse transcription $(R T)$, and $R T$-quantitative polymerase chain reaction ( $q P C R$ ). Total RNA was isolated from the cancerous and paracancerous tissues using TRIzol ${ }^{\circledR}$ reagent (Invitrogen; Thermo Fisher Scientific, Inc.). cDNA was obtained with the Prime-Script ${ }^{\mathrm{TM}}$ RT-PCR kit (Takara Biotechnology Co., Ltd.). AFAP1-AS1 expression was measured by RT-qPCR with the following primer sequences: AFAP1-AS1 forward, 5'-TCGCTCAATGGAGTGACG GCA-3'; and AFAP1-AS1 reverse, 5'-CGGCTGAGACCG CTGAGAACTT-3'. The results were normalized to GAPDH using the following primers: GAPDH forward, 5'-GTCAAC GGATTTGGTCTGTATT-3'; and GAPDH reverse, 5'-AGT CTTCTGGGTGGCAGTGAT-3'. RT-qPCR reactions were performed with ABI7500 System and SYBR Green PCR Master Mix (Thermo Fisher Scientific, Inc.). The PCR was performed using the following conditions: Initial denaturation at $95^{\circ} \mathrm{C}$ for $30 \mathrm{sec} ; 40$ cycles of $95^{\circ} \mathrm{C}$ for $5 \mathrm{sec}$ and $60^{\circ} \mathrm{C}$ for $30 \mathrm{sec}$ with final annealing and extension at $60^{\circ} \mathrm{C}$ for $60 \mathrm{sec}$ and $95^{\circ} \mathrm{C}$ for $15 \mathrm{sec}$. The expression level of AFAP1-AS1 in $\mathrm{GC}$ tissues and corresponding paracancerous tissues was analyzed using the $2^{\Delta \Delta \mathrm{Cq}}$ method (18), and the fold change of target genes was analyzed.

Cell culture. The human GC MKN-45, MGC-803 and AGS cell lines were purchased from Shanghai Institute of Cell Biology. Cells were cultured in RPMI-1640 medium supplemented with 10\% FBS (Gibco; Thermo Fisher Scientific, Inc.), penicillin $(100 \mathrm{U} / \mathrm{ml})$, and streptomycin $(100 \mathrm{U} / \mathrm{ml})$ at $37^{\circ} \mathrm{C}$ in a humidified incubator with $5 \% \mathrm{CO}_{2}$.

Small interfering RNA (siRNA) preparation and transfection. For gene knockdown, cells were seeded for 10-12 h and transfected with either $10 \mathrm{nM}$ siRNA or scramble control siRNA (Invitrogen; Thermo Fisher Scientific, Inc.) using Lipofectamine ${ }^{\mathrm{TM}}$ Reagent (Invitrogen; Thermo Fisher Scientific, Inc.) in Opti-MEM (Invitrogen; Thermo Fisher Scientific, Inc.). The sequences of the AFAP1-AS1 targeting siRNAs are presented in Table I.
Transfection experiments were performed at 10-12 $\mathrm{h}$ after cell growth. Cell proliferation was in the logarithmic growth phase, and the cell area size occupied $50-60 \%$ of the culture dish area. Initial detection may be performed at multiple concentration gradients, to detect the interference efficiency of different concentrations of siRNA. Using a $10 \mathrm{nmol}(1.2 \mu \mathrm{l})$ interference concentration as an example, $100 \mu \mathrm{l}$ Opti-MEM, $1.2 \mu 1$ negative control (NC)/interference reagents (siRNA), and $12 \mu \mathrm{l}$ HiPerFect (Qiagen $\mathrm{GmbH}$ ) were added to each tube. After $48 \mathrm{~h}$, the cells were harvested and RT-qPCR was performed as aforementioned to detect the interference efficiency.

MTT assays. Cells were seeded onto 96-well culture plates at a density of $1 \times 10^{3}$ cells per well and incubated at $37^{\circ} \mathrm{C}$ overnight. Then, the cells were incubated with different concentration (1-10 $\mu \mathrm{m}$ ) of curcumin for $72 \mathrm{~h}$. After $24,48,72$ or $96 \mathrm{~h}, 20 \mu \mathrm{l}$ MTT dissolved in $100 \mu$ l RPMI-1640 was added to each well and incubated for an additional $4 \mathrm{~h}$. Then, $150 \mu 1$ dimethyl sulfoxide was added to dissolve formazan crystals. Optical density was detected at a wavelength of $490 \mathrm{~nm}$ using an enzyme-labeled analyzer.

Flow cytometry analysis. The GC MGC-803 cell line was harvested following treatment and washed with PBS. Then, cells were resuspended and stained with fluorescein isothiocyanate-Annexin $\mathrm{V}$ and propidium iodide Apoptosis Detection Kit (cat. no. 556547; BD Biosciences) for apoptosis analysis. A flow cytometer (CYTOMICS FC 500; Beckman Coulter, Inc.) was used to analyze the number of apoptotic MGC-803 cells, and the cell cycle distribution. The fluorescence signal was detected at an emission wavelength of $530 \mathrm{~nm}$. The percentage of cells in the G0-G1, S, and G2-M phases was counted and compared. All data were analyzed using Flowjo v10 software (Tree Star, Inc.).

In vitro wound healing assay. Wounds were created in adherent cells using a $20 \mu \mathrm{l}$ sterile pipette tip after $48 \mathrm{~h}$ of transfection with si-AFAP1-AS1 or si-NC. Cells were then washed 3 times with PBS to remove any free-floating cells and debris. Medium without serum was added, and the cells were incubated at $37^{\circ} \mathrm{C}$ in a humidified atmosphere containing $5 \%$ $\mathrm{CO}_{2}$. Wound healing was observed after 0,12 , or $24 \mathrm{~h}$, respectively, and images of the cells were captured using digital light microscope at $\mathrm{x} 200$ magnification.

Statistical analysis. All experiments were performed at least 3 times, and the data are presented as the mean \pm standard deviation. The differential expression levels of AFAP1-AS1 between the cancerous and adjacent tissues were analyzed with paired Student's t-tests. Categorical data in Table II were analyzed using the $\chi^{2}$ test. A one-way analysis of variance followed by the Bonferroni's post-hoc test was used to evaluate numerical differences for multiple comparisons. For GC tissues and the corresponding non-cancerous adjacent tissues, the fold change of the target gene was calculated using the $2^{-\Delta \Delta C q}$ method (15). All statistical analyses were performed with SPSS 23 software (IBM Corp.) and GraphPad Prism 7.0 (GraphPad Software, Inc.). P $<0.05$ was considered to indicate a statistically significant difference. 
Table I. Sequences of the AFAP1-AS1-targeting siRNAs.

\begin{tabular}{llc}
\hline siRNAs & \multicolumn{1}{c}{ Forward } & \multicolumn{1}{c}{ Reverse } \\
\hline Negative control & 5'-GCGACGAUCUGCCUAAGA-3' & 5'-AUCUUAGGCAGAUCGUCG-3' \\
siRNA1 & 5'-GUCCCAGCUUACACUUGUATT-3' & 5'-UACAAGUGUAAGCUGGGACTT-3' \\
siRNA2 & 5'-GGGCUUCAAUUUACAAGCATT-3' & 5'-UGCUUGUAAAUUGAAGCCCTT-3' \\
siRNA3 & 5'-CCUAUCUGGUCAACACGUATT-3' & 5'-UACGUGUUGACCAGAUAGGTT-3'
\end{tabular}

siRNA, small interfering RNA.

Table II. Associations between AFAP1-AS1 and clinicopathological characteristic of 52 primary gastric cancer samples.

\begin{tabular}{|c|c|c|c|c|}
\hline Variables & $\begin{array}{l}\text { Over expression of } \\
\text { AFAP1-AS1, n (\%) }\end{array}$ & $\begin{array}{l}\text { Normal expression of } \\
\text { AFAP1-AS1, }(\%)\end{array}$ & $\chi^{2}$ value & P-value \\
\hline Age, y & & & 0.084 & 0.772 \\
\hline$\geq 60$ & $20(52.6)$ & $6(42.9)$ & & \\
\hline$<60$ & $18(47.4)$ & $8(57.1)$ & & \\
\hline Sex & & & 2.608 & 0.106 \\
\hline Male & $28(73.7)$ & $7(50)$ & & \\
\hline Female & $10(26.3)$ & $7(50)$ & & \\
\hline Diameter, $\mathrm{cm}$ & & & 3.791 & 0.052 \\
\hline$\geq 5$ & $13(34.2)$ & $9(64.3)$ & & \\
\hline$<5$ & $25(65.8)$ & $5(35.7)$ & & \\
\hline Sites & & & 0.259 & 0.611 \\
\hline Upper & $16(47.1)$ & $7(50)$ & & \\
\hline Lower & $22(52.9)$ & $7(50)$ & & \\
\hline Differentiation & & & 1.481 & 0.224 \\
\hline Well/Mid & $18(47.4)$ & $4(28.6)$ & & \\
\hline Poorly & $20(52.6)$ & $10(71.4)$ & & \\
\hline Lymphatic metastasis & & & 6.656 & 0.010 \\
\hline Yes & $12(31.6)$ & $10(71.4)$ & & \\
\hline No & $26(68.4)$ & $4(28.6)$ & & \\
\hline TNM stage & & & 7.137 & 0.008 \\
\hline $\mathrm{I}+\mathrm{II}$ & $14(36.8)$ & $11(78.6)$ & & \\
\hline III+IV & $24(63.2)$ & $3(21.4)$ & & \\
\hline
\end{tabular}

AFAP1-AS, actin filament-associated protein 1 antisense RNA 1; TNM, tumor node metastasis staging.

\section{Results}

Expression of LncRNA AFAPl-AS1 in GC tissues. RT-qPCR was used to examine AFAP1-AS1 mRNA expression in 52 cases of GC. The results demonstrated that IncRNA AFAP1-AS1 expression levels were significantly upregulated in GC tissues when compared with the corresponding non-cancerous tissues $(\mathrm{n}=52 ; \mathrm{P}<0.05$; Fig. 1). Evaluation of the differences in the clinicopathological characteristics between the patients with primary GC with and without AFAP1-AS1 overexpression revealed that the overexpression of AFAP1-AS1 was positively associated with clinical stage and lymph node metastasis, although they were not significantly associated with sex, age, tumor size, tumor location or degree of differentiation in patients with GC (Table II).
Expression of LncRNA AFAP1-AS1 in GC cells. The expression levels of AFAP1-AS1 in the GC MGC-803 and AGS cell lines were significantly increased compared with that observed in the normal gastric GES-1 cell line $(\mathrm{P}<0.05)$; the expression level in MGC-803 cells was the highest. However, the expression of AFAP1-AS1 in the GC cell line MKN45 was not significantly different when compared with the normal gastric cells (Fig. 2).

Effects of AFAPI-AS1 knockdown on the proliferation of the $G C$ cell line MGC-803. The GC cell line MGC-803, which exhibited the highest level of AFAP1-AS1 expression, was selected for subsequent experiments to determine the transfection efficiency. As indicated in Fig. 3A, the knockout effects 

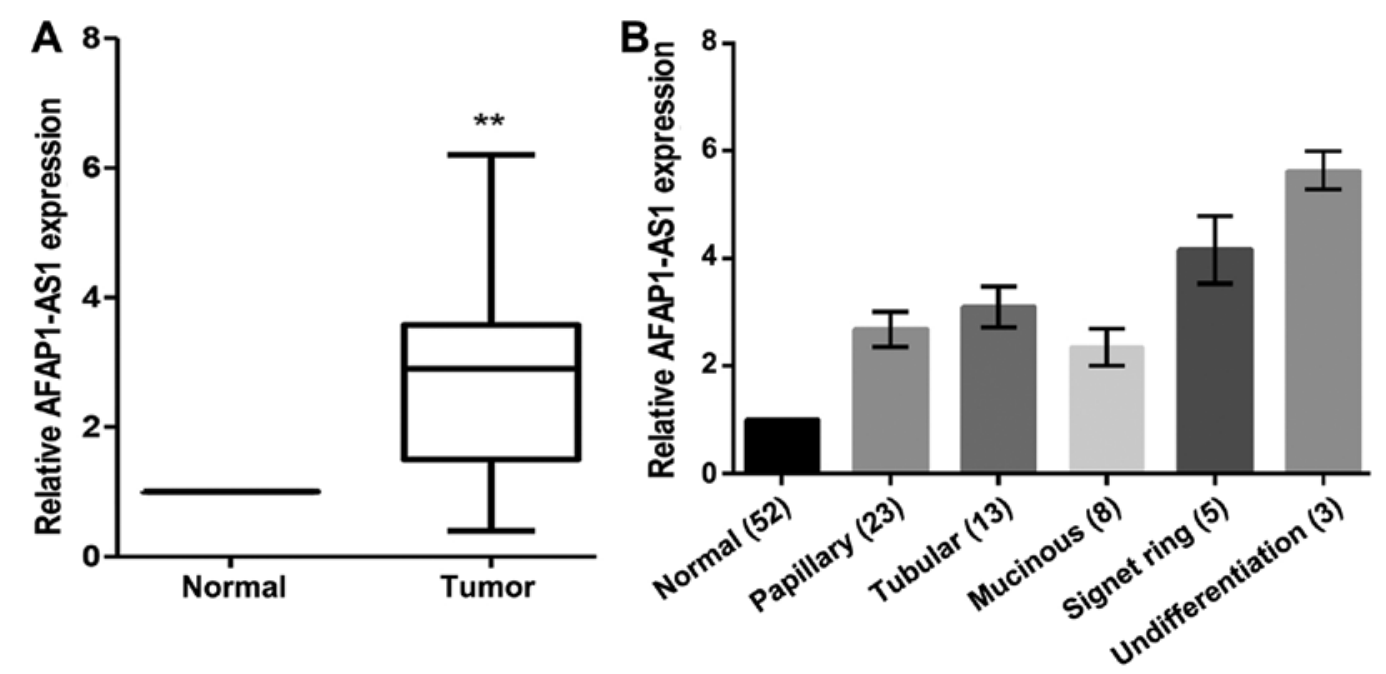

Figure 1. Expression of LncRNA AFAP1-AS1 is detected by reverse transcription-quantitative polymerase chain reaction in 52 GC tissues. (A) AFAP1-AS expression is upregulated in GC tissues when compared with adjacent para-cancer tissues ( $\mathrm{n}=52$ ). (B) AFAP1-AS1 expression in different pathological types of GC tissues when compared with adjacent para-cancer tissues. ${ }^{* *} \mathrm{P}<0.01$ vs. Normal. AFAP1-AS, actin filament-associated protein 1 antisense RNA 1; lncRNA, long non-coding RNA; GC, gastric cancer.

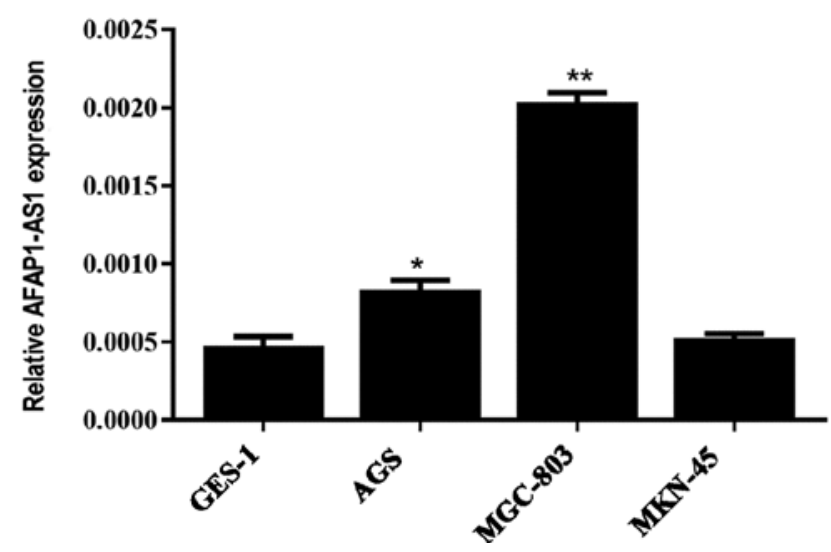

Figure 2. AFAP1-AS1 expression in GES-1 cells and 3 gastric cancer cell lines was evaluated using reverse transcription-quantitative polymerase chain reaction and presented as fold change relative to the expression in GES-1. ${ }^{*} \mathrm{P}<0.05$ and ${ }^{* *} \mathrm{P}<0.01$ vs. GES-1. AFAP1-AS, actin filament-associated protein 1 antisense RNA 1.

of SiRNA1 and siRNA2 were more efficient compared with siRNA3, with knockdown efficiencies of $\sim 65$ and $\sim 50 \%$, respectively. Therefore, these 2 interference sequences were selected for co-transfection in order to examine the effects on the functions of GC cells.

Using the GC cell line MGC-803, an MTT assay was performed to generate curves of cell growth over 5 days and the results determined the proliferation rate of GC MGC-803. Cell proliferation was significantly inhibited following AFAP1-AS1 downregulation (Fig. 3B). The results revealed that transfection of MGC-803 cells with siRNA1 and siRNA2 resulted in a significant decrease in cell proliferation when compared with the control siRNA-transfected MGC-803 cells (Fig. 3B).

Effects of AFAP1-AS1 on apoptosis and the cell cycle in $M G C-803$ cells. Flow cytometry was conducted to detect the changes in apoptosis and the cell cycle in MGC-803 cells following transfection with si-AFAP1-AS1. As demonstrated in Fig. 4A and B, there was no significant difference in the rate of apoptosis between the NC and siRNA1 groups, but the MGC cells apoptosis rate was significantly increased in the siRNA2 group $(\mathrm{P}<0.01)$.

Following transfection of siRNAs in the MGC803 cell line, it was demonstrated that there was no marked difference in the rate of apoptosis between the NC and siRNA1 groups following APAP1-AS1 silencing $(\mathrm{P}=0.1064)$. However, the proportion of cells in the $\mathrm{G}_{0} / \mathrm{G}_{1}$ phase following APAP1-AS1 knockdown was significantly increased in the siRNA1 and siRNA2 groups compared with that observed in the NC group $(\mathrm{P}<0.05 ; \mathrm{P}<0.01$ respectively; Fig. $4 \mathrm{C})$, suggesting that APAP1-AS1 may affect the regulation of the cell cycle in GC.

Effects of AFAP1-AS1 on migratory capabilities in the GC $M G C-803$ cell line. Using the GC cell line MGC-803, cell scratches were created at 0,12 , and $24 \mathrm{~h}$ after cell interference and images of the cells were captured. As indicated in Fig. 5, the migratory ability of the GC MGC-803 cell line was significantly inhibited following knockdown of AFAP1-AS1.

\section{Discussion}

An increasing body of evidence has demonstrated that the upregulation of lncRNAs is involved in the tumorigenesis and metastasis of GC, a type of malignant neoplasm frequently observed in East Asia. lncRNAs are a class of nucleic acid sequences measuring $>200$ bps in length (19). A number of studies have demonstrated that IncRNAs participate in a wide range of physiological processes; they may regulate gene expression at the transcriptional and post-transcriptional level, and may also regulate cellular functions through various mechanisms (20). IncRNAs are known to be closely associated with the development and progression of cancer, and recently have become a key area of medical research, with potential in future clinical practice.

$\mathrm{GC}$ is one of the most common types of malignant tumors in humans and is a serious threat to human health. Its incidence 

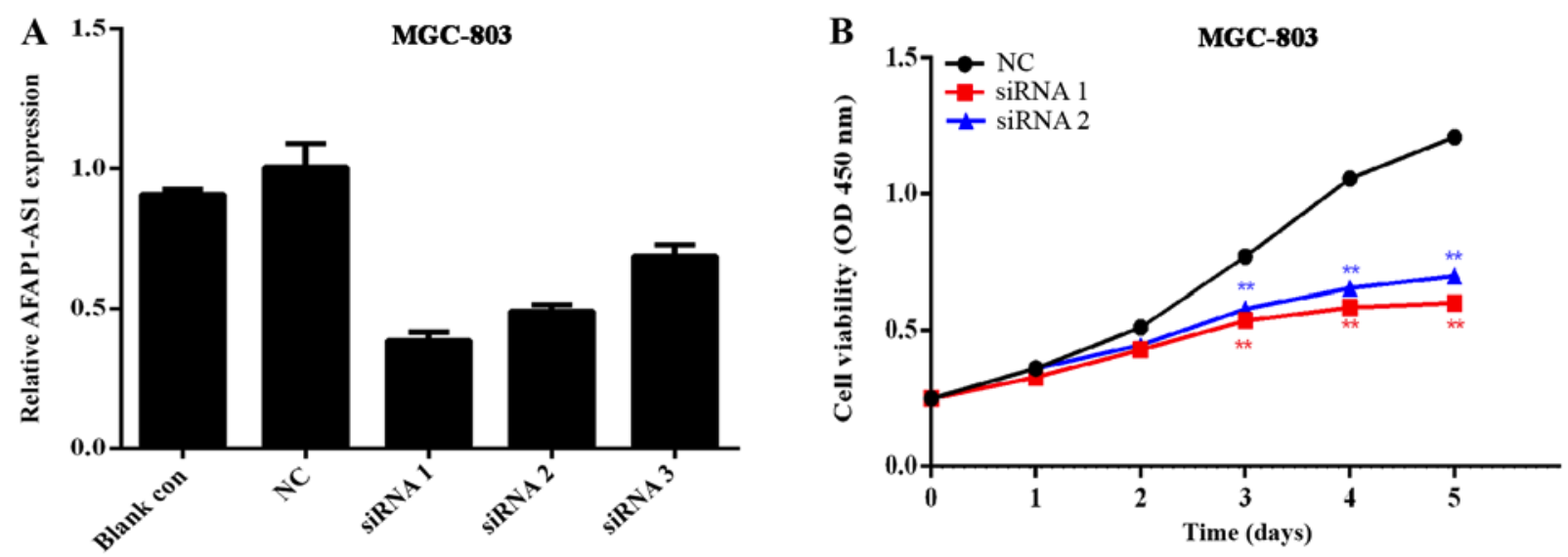

Figure 3. The AFAP1 expression and cell viability following MGC803 knock down. (A) Detection of AFAP1-AS1 knockdown efficiency in the gastric cancer cell line MGC-803. Compared to the NC group, the knockdown efficiency of siRNA1 was $\sim 65 \%$ and for siRNA2 was $~ 50 \%$. (B) MTT assays in the MGC803 cell line following alteration of the expression of AFAP1-AS1. AFAP1-AS, actin filament-associated protein 1 antisense RNA 1; siRNA, small interfering RNA; NC, negative control; OD, optical density. ${ }^{* *} \mathrm{P}<0.01$ vs. control.
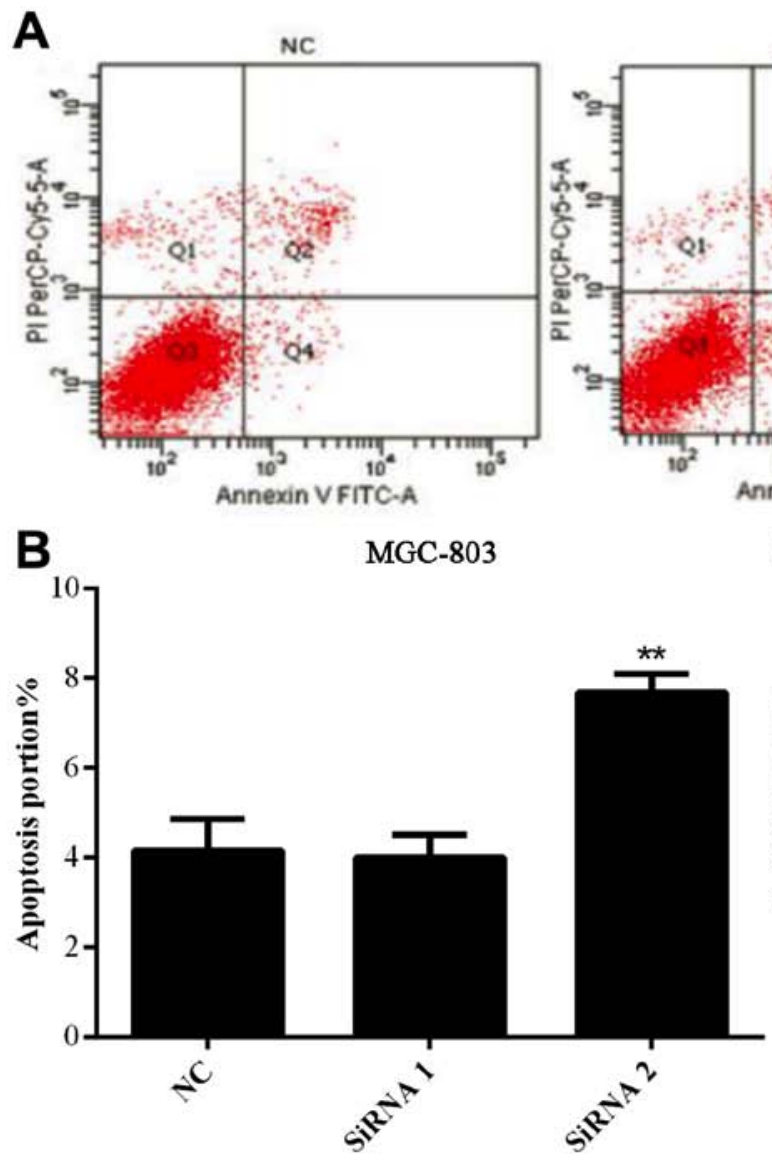
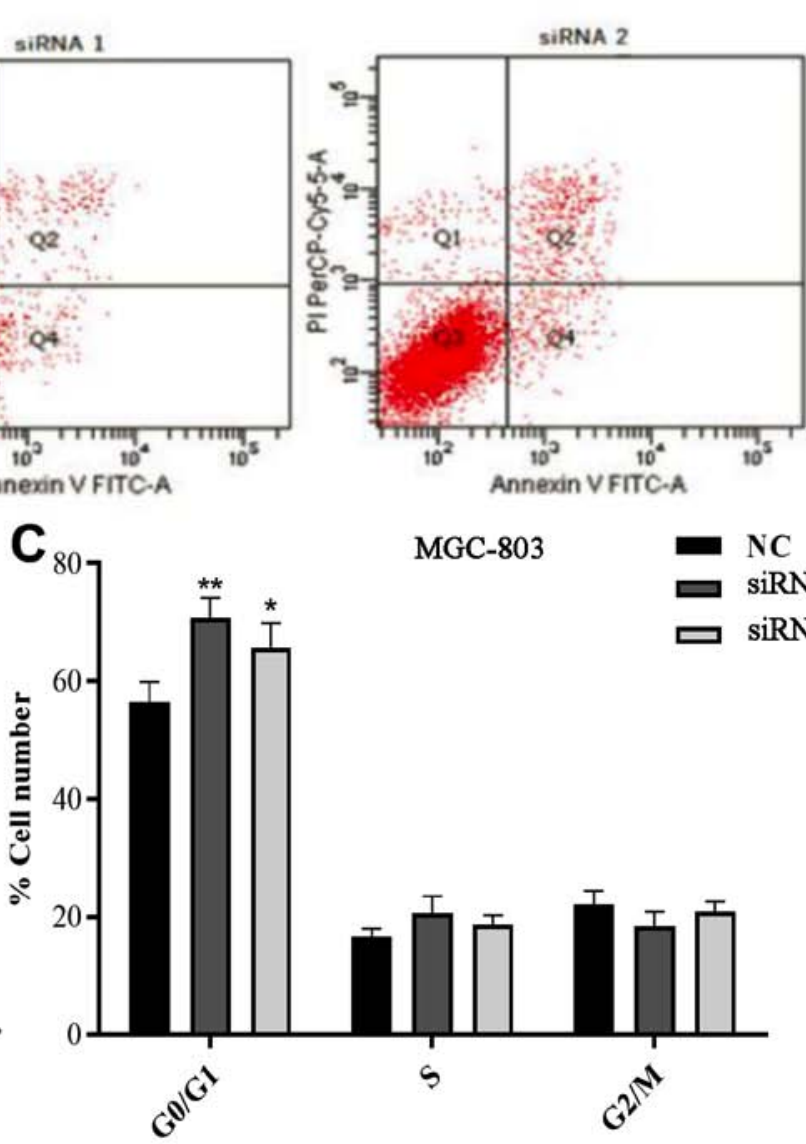

Figure 4. Effects of AFAP1-AS1 on apoptosis and the cell cycle in MGC-803 cells. (A and B) Flow cytometry of apoptosis in MGC-803 cells transfected with siRNA1 and siRNA2. Specific AFAP1-AS1 siRNAs increased the rate of apoptosis in MGC-803 cells. (A) Representative scatter plot demonstrating levels of apoptosis. (B) Quantification of flow cytometry data. (C) Cell cycle phase distributions were analyzed using flow cytometry. AFAP1-AS, actin filament-associated protein 1 antisense RNA 1; siRNA, small interfering RNA; NC, negative control; FITC, fluorescein isothiocyanate; PI, propidium iodide. ${ }^{*} \mathrm{P}<0.05$ and ${ }^{* *} \mathrm{P}<0.01$ vs. negative control.

rate has continuously risen over previous years and China has one of the highest incidence rates of GC in the world. Chen et al (21) demonstrated that in China, the GC incidence was the second most common type of tumor diagnosed. The traditional treatments, including surgery, radiotherapy and chemotherapy, are not sufficiently effective for patients with advanced stage GC. Therefore, it is important to identify valuable biomarkers to improve the percentage of accurate early diagnoses in patients with GC. According to previous studies, a number of biomarkers have been identified for the diagnosis 


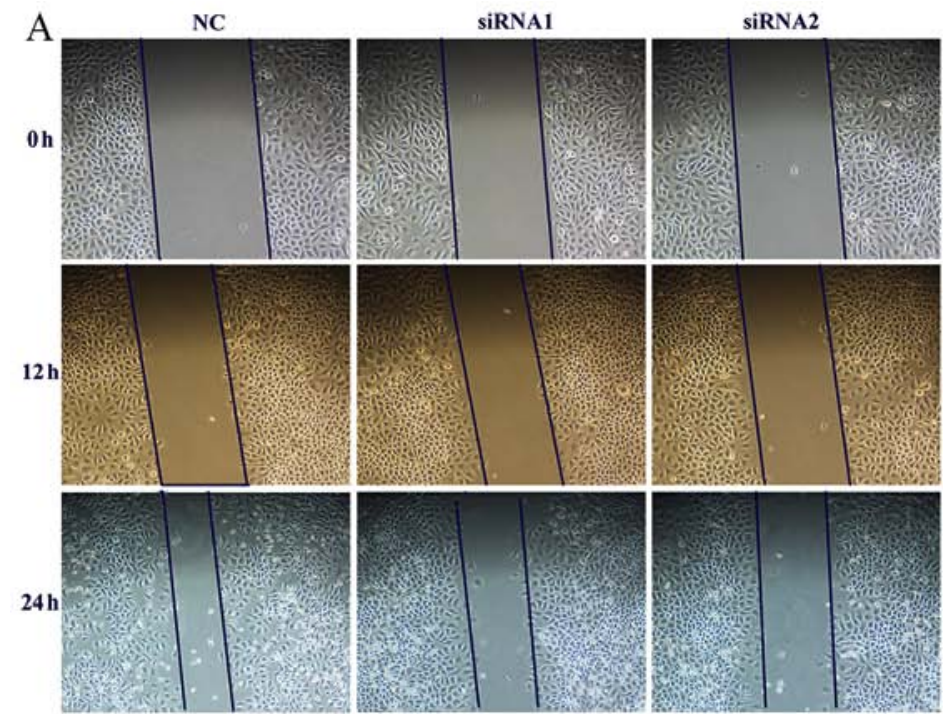

B

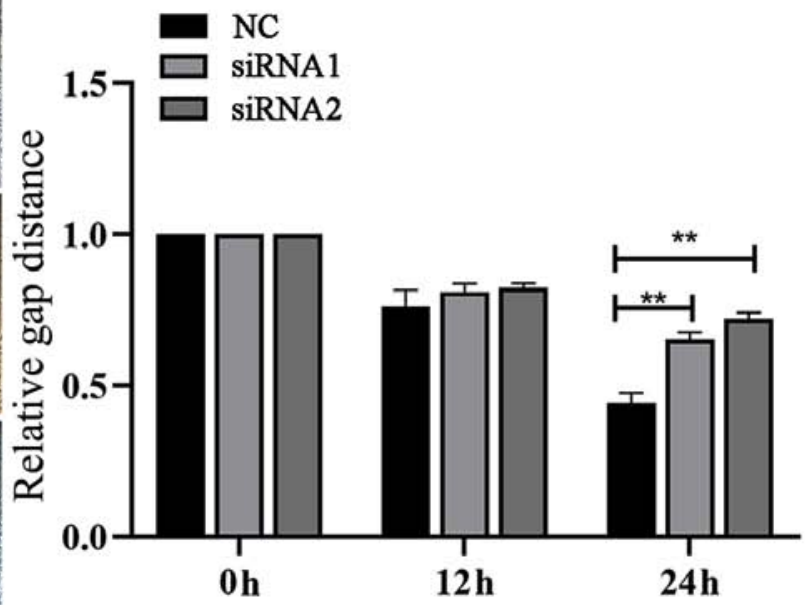

Figure 5. Effects of AFAP1-AS1 on the migratory ability of the gastric cancer MGC-803 cell line. (A) Wound healing assays were conducted to assess the migratory capabilities of MGC-803 cells transfected with si-AFAP1-AS1. (B) The data are summarized as the relative gap distance. AFAP1-AS, actin

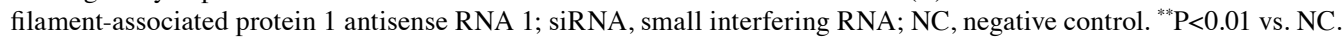

or prognosis of patients with cancer $(22,23)$; among these, lncRNAs are a key area of interest.

Lately, AFAP1-AS1 has been revealed to function primarily as an oncogene, regulating gene expression by affecting mRNA and the corresponding transcriptional protein. A previous profiling study suggested that the upregulation of IncRNA AFAP1-AS1 affected the proliferation, invasion and survival rates of tongue squamous cell carcinoma via the Wnt/ $\beta$-catenin signaling pathway (24). Yuan et al (25) revealed that the AFAP1-AS1/miR-320a/RBPJ axis regulates laryngeal carcinoma cell stemness and chemoresistance. An additional previous study indicated that the upregulation of lncRNA AFAP1-AS1 expression was associated with progression and poor prognosis in nasopharyngeal carcinoma (26). However, to the best of our knowledge, its function in carcinogenesis and tumor progression in GC remains unknown.

In the present study, the results of RT-qPCR demonstrated that 1ncRNA AFAP1-AS1 expression in tumor tissues was significantly increased compared with that of non-cancerous tissues in 52 matched pairs of patient samples, which is consistent with a previous study (27). In addition, the association between AFAP1-AS1 and clinicopathological characteristics revealed that the overexpression of AFAP1-AS1 was not aberrantly associated with ex, age, tumor size, tumor location or degree of differentiation in patients with GC, but was positively associated with clinical stage and lymph node metastasis. Higher AFAP1-AS1 mRNA expression levels were also associated with the occurrence of lymph node metastasis.

To further understand the biological function of AFAP1-AS1 in GC cells, in vitro experiments were conducted. The GC MGC-803 cell line exhibited the highest AFAP1-AS1 expression when compared with the gastric normal cell line GES-1, within a panel of GC cell lines. Therefore, the MGC-803 cell line was selected for further analysis. The results demonstrated that the proliferation rate of MGC-803 cells was significantly inhibited following knockdown of AFAP1-AS1 expression.
In addition, the proportion of cells in the G0/G1 phase following knockdown was significantly increased compared with that observed in the NC group, suggesting that AFAP1-AS1 may have an effect on the regulation of the GC cell cycle. However, the effect of APAP1-AS1 on the rate of apoptosis was not as marked as expected. In addition, the migratory ability of the GC MGC-803 cell line was significantly inhibited following knockdown of AFAP1-AS1 expression.

The present study confirmed that AFAP1-AS1 is highly expressed in human GC tissues and cell lines, and that it significantly affected tumor cell invasion and proliferation. However, its specific mechanism has not been fully elucidated and requires additional investigation.

In conclusion, the results of the present study demonstrated that lncRNA AFAP1-AS1 is highly expressed in GC, suggesting that AFAP1-AS1 may be a GC-specific lncRNA and serve play an important role in the development of GC. Knockdown of lncRNA AFAP1-AS1 inhibited cell proliferation and migration in MGC-803 cells. These results indicated that lncRNA AFAP1-AS1 may function as an oncogene in GC and may be a novel marker for the diagnosis and therapeutic targeting of GC.

\section{Acknowledgements}

Not applicable.

\section{Funding}

The present study was supported by the Jiangsu Natural Science Foundation (grant no. BK20151087), awarded to Professor Hongyong Cao.

\section{Availability of data and materials}

The datasets used and/or analyzed during the present study are available from the corresponding author on reasonable request. 


\section{Authors' contributions}

ZXL designed the project, collected patient data and performed the experiments. ZLD collected the patient data and performed the experiments. DWR analyzed the data. WWT contributed to the design of the project, wrote the original draft manuscript and provided funding. HYC supervised the project throughout, reviewed and edited the manuscript, provided funding and collected the patient data.

\section{Ethics approval and consent to participate}

The present study was approved by the Ethics Committee of Nanjing First Hospital, Nanjing Medical University (Jiangsu, China). Written informed consent was obtained from all of the patients prior to participation.

\section{Patient consent for publication}

Written informed consent was obtained from all of the patients prior to participation.

\section{Competing interests}

The authors declare that they have no competing interests.

\section{References}

1. Torre LA, Bray F, Siegel RL, Ferlay J, Lortet-Tieulent J and Jemal A: Global cancer statistics, 2012. CA Cancer J Clin 65 : 87-108, 2015

2. Ferlay J, Soerjomataram I, Dikshit R, Eser S, Mathers C, Rebelo M, Parkin DM, Forman D and Bray F: Cancer incidence and mortality worldwide: Sources, methods and major patterns in GLOBOCAN 2012. Int J Cancer 136: E359-E386, 2015.

3. Yagi K, Nozawa Y, Endou S and Nakamura A: Diagnosis of early gastric cancer by magnifying endoscopy with NBI from viewpoint of histological imaging: Mucosal patterning in terms of white zone visibility and its relationship to histology. Diagn Ther Endosc 2012: 954809, 2012.

4. Yoon SH, Kim YH, Lee YJ, Park J, Kim JW, Lee HS and Kim B: Tumor heterogeneity in human epidermal growth factor receptor 2 (HER2)-positive advanced gastric cancer assessed by CT texture analysis: Association with survival after trastuzumab treatment. PLoS One 11: e0161278, 2016.

5. Biffi R, Botteri E, Cenciarelli S, Luca F, Pozzi S, Valvo M, Sonzogni A, Chiappa A, Leal Ghezzi T, Rotmensz N, et al: Impact on survival of the number of lymph nodes removed in patients with node-negative gastric cancer submitted to extended lymphnode dissection. Eur J Surg Oncol 37: 305-311, 2011

6. Yang G, Lu X and Yuan L: LncRNA: A link between RNA and cancer. Biochim Biophys Acta 1839: 1097-1109, 2014.

7. Bhan A, Soleimani M and Mandal SS: Long noncoding RNA and cancer: A new paradigm. Cancer Res 77: 3965-3981, 2017.

8. Esteller M: Non-coding RNAs in human disease. Nat Rev Genet 12: 861-874, 2011.

9. Gupta RA, Shah N, Wang KC, Kim J, Horlings HM, Wong DJ, Tsai MC, Hung T, Argani P, Rinn JL, et al: Long non-coding RNA HOTAIR reprograms chromatin state to promote cancer metastasis. Nature 464: 1071-1076, 2010.
10. Li W, Zheng J, Deng J, You Y, Wu H, Li N, Lu J and Zhou Y: Increased levels of the long intergenic non-protein coding RNA POU3F3 promote DNA methylation in esophageal squamous cell carcinoma cells. Gastroenterology 146: 1714-1726.e5, 2014.

11. Tsang WP, Ng EK, Ng SS, Jin H, Yu J, Sung JJ and Kwok TT: Oncofetal H19-derived miR-675 regulates tumor suppressor RB in human colorectal cancer. Carcinogenesis 31: 350-358, 2010.

12. Yang SL, Lin RX, Si LH, Cui MH, Zhang XW and Fan LM: Expression and functional role of long non-coding RNA AFAP1-AS1 in ovarian cancer. Eur Rev Med Pharmacol Sci 20: 5107-5112, 2016

13. Ma F, Wang SH, Cai Q, Zhang MD, Yang Y and Ding J: Overexpression of LncRNA AFAP1-AS1 predicts poor prognosis and promotes cells proliferation and invasion in gallbladder cancer. Biomed Pharmacother 84: 1249-1255, 2016.

14. Luo HL, Huang MD, Guo JN, Fan RH, Xia XT, He JD and Chen XF: AFAP1-AS1 is upregulated and promotes esophageal squamous cell carcinoma cell proliferation and inhibits cell apoptosis. Cancer Med 5: 2879-2885, 2016.

15. Han X, Wang L, Ning Y, Li S and Wang Z: Long non-coding RNA AFAP1-AS1 facilitates tumor growth and promotes metastasis in colorectal cancer. Biol Res 49: 36, 2016.

16. Fu XL, Liu DJ, Yan TT, Yang JY, Yang MW, Li J, Huo YM, Liu W, Zhang JF, Hong J, et al: Analysis of long non-coding RNA expression profiles in pancreatic ductal adenocarcinoma. Sci Rep 6: 33535, 2016.

17. Mahul BA, Stephen B, Edge, Frederick L, et al: AJCC Cancer Staging Manual. https://cancerstaging.org/references-tools/ deskreferences/pages/default.aspx. Accessed: September 5, 2018.

18. Livak KJ and Schmittgen TD: Analysis of relative gene expression data using real-time quantitative PCR and the 2(-Delta Delta C(T)) method. Methods 25: 402-408, 2001.

19. Mercer TR, Dinger ME and Mattick JS: Long non-coding RNAs: Insights into functions. Nat Rev Genet 10: 155-159, 2009.

20. Bergmann JH and Spector DL: Long non-coding RNAs: Modulators of nuclear structure and function, Curr Opin Cell Biol 26: 10-18, 2014.

21. Chen W, Zheng R, Baade PD, Zhang S, Zeng H, Bray F, Jemal A, $\mathrm{Yu}$ XQ and He J: Cancer statistics in China, 2015. CA Cancer J Clin 66: 115-132, 2016.

22. Wu L and Qu X: Cancer biomarker detection: Recent achievements and challenges. Chem Soc Rev 44: 2963-2997, 2015.

23. Armitage EG and Barbas C: Metabolomics in cancer biomarker discovery: Current trends and future perspectives. J Pharm Biomed Anal 87: 1-11, 2014.

24. Wang ZY, Hu M, Dai MH, Xiong J, Zhang S, Wu HJ, Zhang SS and Gong ZJ: Upregulation of the long non-coding RNA AFAP1-AS1 affects the proliferation, invasion and survival of tongue squamous cell carcinoma via the $\mathrm{Wnt} / \beta$-catenin signaling pathway. Mol Cancer 17: 3, 2018.

25. Yuan Z, Xiu C, Song K, Pei R, Miao S, Mao X, Sun J and Jia S: Long non-coding RNA AFAP1-AS1/miR-320a/RBPJ axis regulates laryngeal carcinoma cell stemness and chemoresistance. J Cell Mol Med 22: 4253-4262, 2018.

26. Bo H, Gong Z, Zhang W, Li X, Zeng Y, Liao Q, Chen P, Shi L, Lian Y, Jing Y, et al: Upregulated long non-coding RNA AFAP1-AS1 expression is associated with progression and poor prognosis of nasopharyngeal carcinoma. Oncotarget 6: 20404-1829, 2015.

27. Lu X, Zhou C, Li R, Liang Z, Zhai W, Zhao L and Zhang S: Critical role for the long non-coding RNA AFAP1-AS1 in the proliferation and metastasis of hepatocellular carcinoma. Tumor Biol 37: 9699-9707, 2016.

This work is licensed under a Creative Commons Attribution-NonCommercial-NoDerivatives 4.0 International (CC BY-NC-ND 4.0) License. 